\title{
Recent progress in translational research on neurovascular and neurodegenerative disorders
}

Hans-Ulrich Demuth ${ }^{\mathrm{a}}$, Rick M. Dijkhuizen ${ }^{\mathrm{b}}$, Tracy D. Farr ${ }^{\mathrm{c}}$, Mathias Gelderblom ${ }^{\mathrm{d}}$, Karen Horsburgh $^{\mathrm{e}}$, Costantino Iadecola ${ }^{\mathrm{f}}$, Damian D. Mcleod ${ }^{\mathrm{g}}$, Dominik Michalski ${ }^{\mathrm{h}}$, Tim H. Murphy ${ }^{\mathrm{i}}$, Josune Orbe ${ }^{\mathrm{j}}$, Willem M. Otte ${ }^{\mathrm{b}, \mathrm{k}}$, Gabor C. Petzold ${ }^{\mathrm{l}}$, Nikolaus Plesnila ${ }^{\mathrm{m}}$, Georg Reiser $^{\mathrm{n}}$, Klaus G. Reymann ${ }^{\circ}$, Maria A. Rueger ${ }^{\mathrm{p}}$, Dorothee Saur ${ }^{\mathrm{h}}$, Sean I. Savitz ${ }^{\mathrm{q}}$, Stephan Schilling ${ }^{\mathrm{a}}$, Neil J. Spratt ${ }^{\mathrm{g}}$, Renée J. Turner ${ }^{\mathrm{r}}$, Raghu Vemuganti ${ }^{\mathrm{s}}$, Denis Vivien ${ }^{\mathrm{t}}$, Manuel Yepes ${ }^{\mathrm{u}}$, Marietta Zille ${ }^{\mathrm{v}}$ and Johannes Boltze ${ }^{\mathrm{w}, *}$ for the ISN\&N meeting contributors ${ }^{a}$ Department of Drug Design and Target Validation, Fraunhofer Institute for Cell Therapy and Immunology (IZI-MWT), Halle/Saale, Germany

${ }^{\mathrm{b}}$ Biomedical MR Imaging and Spectroscopy Group, Center for Image Sciences, University Medical Center Utrecht, The Netherlands

${ }^{\mathrm{c}}$ School of Life Sciences, University of Nottingham, Nottingham, UK

${ }^{\mathrm{d}}$ Department of Neurology, University Medical Center Hamburg-Eppendorf, Hamburg, Germany

${ }^{\mathrm{e}}$ Centre for Neuroregeneration, University of Edinburgh, Edinburgh, UK

${ }^{\mathrm{f}}$ Brain and Mind Research Institute, Weill Cornell Medicine, New York, NY, USA

${ }^{\mathrm{g}}$ University of Newcastle, Hunter Medical Research Institute and Hunter New England Local Health District, Newcastle, Australia

${ }^{\mathrm{h}}$ Department of Neurology, University of Leipzig, Leipzig, Germany

${ }^{\mathrm{i}}$ Department of Psychiatry, University of British Columbia, Vancouver, Canada

${ }^{\mathrm{j}}$ Atherothrombosis Laboratory, Centre for Applied Medical Research, University of Navarra, Pamplona, Spain

${ }^{\mathrm{k}}$ Department of Pediatric Neurology, Brain Center Rudolf Magnus, University Medical Center Utrecht, Utrecht, The Netherlands

${ }^{1}$ German Center for Neurodegenerative Diseases, Bonn, Germany

${ }^{\mathrm{m}}$ Institute for Stroke and Dementia Research (ISD), University of Munich Medical Center;

Munich Cluster of Systems Neurology (Synergy), LMU Munich, Germany

${ }^{\mathrm{n}}$ Institute for Neurobiochemistry, University of Magdeburg, Magdeburg, Germany

${ }^{\circ}$ Neuropharmacology Lab, Leibniz Institute for Neurobiology, Magdeburg, Germany

${ }^{\mathrm{p}}$ Department of Neurology, University Hospital of Cologne, Cologne, Germany

${ }^{\mathrm{q}}$ Department of Neurology, UTHealth Medical School, Houston, TX, USA

${ }^{\mathrm{r}}$ Adelaide Medical School and Adelaide Centre for Neuroscience Research, The University of Adelaide, Adelaide, Australia

${ }^{\mathrm{s}}$ Deptartment of Neurological Surgery, University of Wisconsin and William S. Middleton VA Hospital, Madison, WI, USA

\footnotetext{
${ }^{*}$ Corresponding author: Johannes Boltze, MD, PhD, Fraunhofer Research Institution for Marine Biotechnology, Mönkhofer Weg 239a, 23562 Lübeck, Germany. Tel.: +49 0451 38444820; Fax: +49 0451 38444812; E-mail: johannes.boltze@ emb.fraunhofer.de.
} 
${ }^{\mathrm{t}}$ Cell Biology and Clinical Research Department, Medical Center, Université Caen-Normandie, GIP Cyceron; Inserm, Inserm UMR-S U919, Serine Proteases and Pathophysiology of the neurovascular Unit, Caen, France "Department of Neurology, Emory University, Atlanta, GA, USA

${ }^{\mathrm{v}}$ Department of Neurology and Neuroscience, The Burke Medical Research Institute, Weill Medical College of Cornell University, White Plains, NY, USA

${ }^{\mathrm{w}}$ Department of Medical Cell Technology, Fraunhofer Research Institution for Marine Biotechnology; Institute for Medical and Marine Biotechnology, University of Lübeck, Lübeck, Germany

\begin{abstract}
The already established and widely used intravenous application of recombinant tissue plasminogen activator as a re-opening strategy for acute vessel occlusion in ischemic stroke was recently added by mechanical thrombectomy, representing a fundamental progress in evidence-based medicine to improve the patient's outcome. This has been paralleled by a swift increase in our understanding of pathomechanisms underlying many neurovascular diseases and most prevalent forms of dementia. Taken together, these current advances offer the potential to overcome almost two decades of marginally successful translational research on stroke and dementia, thereby spurring the entire field of translational neuroscience. Moreover, they may also pave the way for the renaissance of classical neuroprotective paradigms.

This review reports and summarizes some of the most interesting and promising recent achievements in neurovascular and dementia research. It highlights sessions from the 9th International Symposium on Neuroprotection and Neurorepair that have been discussed from April 19th to 22nd in Leipzig, Germany. To acknowledge the emerging culture of interdisciplinary collaboration and research, special emphasis is given on translational stories ranging from fundamental research on neurodeand -regeneration to late stage translational or early stage clinical investigations.
\end{abstract}

Keywords: Alzheimer's disease, brain, cerebral ischemia, cerebral small vessel disease, dementia, experimental therapy, hemorrhage, in vivo imaging, neuroimmunology, neuroprotection, neurorepair, sex differences, stroke, translational research, vascular cognitive impairment

\section{Introduction}

Neurovascular research is at a turning point. The successful attempt to widen the therapeutic time window for ischemic stroke (Hacke et al., 2008) has recently been added by a handful of randomized controlled clinical trials demonstrating efficacy of novel intravascular recanalization procedures (i.e. mechanical thrombectomy; Campbell et al., 2015) in patients with large vessel occlusion, a situation that is usually associated with malignant edema formation and high mortality. After numerous translational failures of neuroprotective attempts during the last decades (e.g. NXY-059 in the SAINT trials; Diener et al., 2008), this situation might pave the way for a novel concept of combined endovascular and neuroprotective therapies (Henninger \& Fisher, 2016; Lo \& Ning, 2016). At the same time, progress in the treatment of Alzheimer's disease (AD) and other forms of dementia seems to accelerate (Venigalla et al., 2016; Deak et al., 2016). We also gain more and more detailed insight on the role of gene and protein expression in Alzheimer's disease. For example, the presence of pyroglutamylated $A \beta$ deposits correlates well with mental status and disease progression (Mandler et al., 2014). This knowledge might ultimately lead to novel therapeutic target candidates. In vascular dementia, the role of central and peripheral inflammatory responses is increasingly recognized, exhibiting interesting similarities to what has been described in acute neurovascular insults such as stroke (Kaiser et al., 2014). Based on our augmented understanding of underlying pathophysiological mechanisms, the advent of novel therapeutic options for neurovascular diseases and highly prevalent forms of cognitive impairment becomes more likely.

The biannual International Symposium on Neuroprotection and Neurorepair (ISN\&N) meeting series aims to bring together leading experts and internationally recognized pioneers in the field to discuss recent advances in fundamental research, translational programs, and clinical implementation. Continuing the tradition of previous meetings (Boltze et al., 2011, 2012), the 9th ISN\&N was jointly organized by the University of Leipzig, FraunhoferInstitute for Cell Therapy and Immunology, Leipzig and the Fraunhofer Research Institution of Marine 
Biotechnology, Lübeck. It took place in Leipzig, Germany from April 19th to 22nd, 2016 and became the largest in the series' history by attracting more than 430 participants from all over the world. This resulted in an atmosphere of intensive scientific exchange and discussions. In this review, we will highlight some of the most exciting findings that have been reported at the 9th ISN\&N. Particular focus is given on translational developments. To achieve this, we preferably selected contributions and sessions providing comprehensive set of data reaching form fundamental discoveries to clinical or at least late stage preclinical results. Special emphasis was given on investigational endpoints being of direct relevance for the clinical situation. Since we might only fail in an attempt to refer to each outstanding talk or fruitful discussion, this review instead provides a cross-selection of excellent contributions from all research disciplines covered by the meeting.

\section{Molecules and mechanisms: News from fundamental research}

\subsection{Noncoding RNAs and neuroprotection}

In mammals, the protein-coding ribonucleic acids (RNAs) constitute $<2 \%$ of the transcriptional output, while noncoding RNAs (ncRNAs) of different classes comprise the remaining $98 \%$. Recent studies showed that experimental stroke alters the expression profiles of various classes of ncRNAs including microRNAs (miRNAs) and long noncoding RNAs (lncRNAs). Hence, the therapeutic potential of ncRNAs in promoting neuroprotection after stroke has been discussed at the meeting.

Rona Giffard (Palo Alto, USA) showed that miRNAs can be manipulated to influence poststroke outcome. She demonstrated that reducing the levels of miR-181 with either pretreatment or post-treatment with an antagomiR-181 effectively decreased the infarction in mouse models of stroke. Particularly, post-treatment leads to long lasting behavioral improvement (Xu et al., 2015). The miR181 antagomiR was observed to target molecules that promote apoptosis, oxidative stress and inflammation. Dr. Giffard further showed that manipulation of miR-210 improves mitochondrial function which promotes survival of newborn neurons as well as reduces inflammation. This dual targeting shows promise to improve post stroke recovery (Ouyang et al., 2015).
Raghu Vemuganti (Madison, USA) showed that, miR-29 and miR-7 are major miRNA families that are considered as pro-survival microRNAs and play essential roles in the healthy brain. Following focal ischemia, miR-29c and miR-7a are downregulated significantly and when these miRNAs were replenished using specific premiRs and/or miRNA mimics, post-ischemic brain damage was curtailed with improved functional recovery indicating their essential neuroprotective role (Pandi et al., 2013; Kim et al., 2016). It was further shown that a lncRNA called FosDT induced after stroke mediates ischemic brain damage and treatment with a siRNA cocktail that targets FosDT significantly protected the brain following focal ischemia. Mechanistically, FosDT siRNA-mediated neuroprotection was associated with curtailed scaffolding of the chromatin modifying proteins Sin3A and coREST to the transcription factor REST that is known to promote neuronal death after stroke (Mehta et al., 2015).

Farida Sohrabji (College Station, USA) showed that outcome following manipulation of miRNAs after stroke depends on both age and sex. A case in point is the miRNA Let7f, which negatively regulates the neuroprotective growth factor insulin growth factor (IGF)-1. In a study using adult and middle aged male and female rats, an antagomir to Let7f (anti-Let7f) was delivered intracerebroventricularly 4 hours post stroke (Selvamani et al., 2012). In adult female rats, anti-Let7f significantly reduced infarct volume and improved sensory motor performance. However, this antagomir had no effect on stroke outcomes in males or ovariectomized females. Furthermore, in middle-aged, acyclic females, anti-Let7f, paradoxically, increased infarct volume. These data emphasize the complex interaction between the constitutive endocrine milieu and miRNA mediators, and underscore the importance of considering both sexes in developing stroke interventions.

Kejie Yin (Ann Arbor, USA) reported that the miR-15a/16-1 cluster is involved in the regulation of post-ischemic angiogenesis. Levels of miR-15a/161 are increased in the cerebrovasculature in mice at 7 days post stroke. Transgenic overexpression of miR-15a/16-1 leads to reduced cerebral blood vessel formation, increased brain infarction and neurological deficits in stroke mice (Yin et al., 2012). A series of in vitro experiments suggested that the miR$15 \mathrm{a} / 16-1$ cluster is a critical mediator in cerebral angiogenesis after ischemic stroke. Pharmacological inhibition may be helpful in developing miR-based 
neurorestorative drugs to promote post-stroke functional recovery.

\subsection{Proteases before, during and after stroke}

The plasminogen activation system was initially thought to be solely involved in the control of fibrin degradation by catalyzing the conversion of plasminogen into plasmin via two serine proteases: tissue-type plasminogen activator (tPA) and urokinase-type plasminogen activator (uPA). However, it has been recently discovered by Manuel Yepes (Atlanta, USA) and colleagues that the control of fibrinolysis is not the only role of tPA and UPA, and that instead both PAs are also found in the synapse where they play a central role in the development of synaptic plasticity via mechanisms that not always require their ability to generate plasmin (Wu et al., 2014, 2015). The group used 8-12 weeks old male wild-type (Wt) C57BL/6J mice for their studies.

Dendritic spines (DSs) are specialized dendritic protrusions that receive most of the excitatory input in the brain; and that are replaced by focal areas of swelling known as varicosities following the onset of global cerebral ischemia in adult 2-5 month old mice (Murphy et al., 2008). Data show that during the recovery phase from an ischemic stroke, neurons located in the peri-infarct cortex release UPA, and the interaction of this UPA with its receptor (UPAR) promotes the reorganization of the actin cytoskeleton and the subsequent re-emergence of dendritic spines from dendritic varicosities. This effect, mediated by uPA-uPAR, induced profilin expression and cofilin phosphorylation, leads to the formation of new synaptic contacts and recovery of neurological function after an ischemic injury. Accordingly, treatment with recombinant uPA (ruPA) promotes dendritic spine recovery and improvement in neurological function after ischemic stroke.

Denis Vivien (Caen, France) provided more insights into the multiple physiological and pathophysiological roles of tPA. The enzyme can act on virtually all cell types of the brain, including neurons, endothelial and glial cells. These actions are conducted by enzymatic or growth-factor-like effects on various molecular substrates or receptors. In addition of its fibrinolytic activity, tPA can also influence NMDA receptors signaling and subsequent neuronal fate. Interestingly, the single chain form of tPA (sc-tPA) is the only one capable to promote NMDA receptors-mediated neuronal death. Accordingly, strategies to prevent the tPA-dependent modulation of NMDA receptor signaling lead to an increased therapeutic window for tPA treatment in experimental stroke (Chevilley et al., 2015).

Josune Orbe (Pamplona, Spain) focused on matrix metalloproteinase (MMP)-10. His group investigated the therapeutic and protective effect of combining tPA/MMP-10 as clot-dissolving and neuroprotective agents after experimental model of ischemic stroke in C57BL/6J male mice (4 months old), as well as the molecular pathways involved. tPA/MMP-10 significantly reduced the infarct size in the ischemic stroke model compared with tPA alone. In vitro, MMP-10 reduced tPA-promoted endothelial ionic permeability, preserved claudin-5 expression and decreased ERK1/2 activation. MMP-10 also prevented tPAmediated neuronal excitotoxicity and $\mathrm{Ca}^{2+}$ influx. These findings indicate that MMP-10 improves tPA-thrombolytic therapy by providing additional cytoprotection. All reported results were obtained from experimental models in rodents. Further investigations are needed to confirm the relevance of these data in clinical situations.

\subsection{Post-translational modifications and regulation of gene expression in neurodegenerative disorders}

It is well-known that neurodegenerative disorders, among those the most prominent, Alzheimer's disease, are characterized by deposition of posttranslationally modified amyloid peptides (Kummer \& Heneka, 2014). Recent studies suggest that appearance of modified $\mathrm{A} \beta$ correlates with disease progression and cognitive status of patients (Morawski et al., 2014; Mandler et al., 2014). Likewise, clinical programs have been initiated to target those forms with novel therapeutics. Moreover, other factors such as activation of endogenous retroviruses might contribute to neurodegeneration (Emmer et al., 2014).

Stephan von Hörsten (Erlangen, Germany) reported about the putative role of N-terminal modifications of mutant Huntingtin (HTT). HD pathology was analyzed in HTT transgenic rats of different age. He pointed out that multiple processes such as limited proteolysis and pyroglutamate formation might act together to generate toxic HTT aggregates in Huntington's Disease. Victoria Gröger (Halle, Germany) reviewed the potential role of human endogenous retroviruses for neurodegenerative disorders. Activation of envelope protein expression elicits a strong immune response and subsequent 
neuronal damage. Jochen Walter reported about phosphorylation of $A \beta$ peptides in Alzheimers's disease $\mathrm{AD}$ and its influence on the aggregation behavior of the amyloid peptide (Rezaei-Ghaleh et al., 2016). Steffen Rossner (Leipzig, Germany) demonstrated the important role of the chemokine CCL2 in Alzheimer's Disease (AD) and the function of a glutaminyl cyclase (isoQC) for activation of the chemokine. Pathology was studied in Tg2576 mice, a mouse model of Alzheimer's disease. Finally, Stephan Schilling (Halle, Germany) reported about endoproteolytic events leading to formation of $A \beta 3$ 42 , which is converted into $\mathrm{N}$-terminally modified pGlu-modified peptides in Alzheimer's disease.

Summarizing, the reports highlighted that modifications of proteins represent attractive anchor points for future drug development.

\section{Where translation begins: Novel pathophysiological insights}

\subsection{Pressure, penumbra and promising acute stroke therapies}

This symposium focused on strong hypothesis driven science and research collaborations with particular potential to translate research from bench to bedside. David Howells (Hobart, Australia) presented data regarding the work of his group using stem cell-derived human neurons as a tool for assessing candidate drugs and therapies (Howells \&
Macleod, 2013). As a prerequisite for translational attempts, these cells were reproducibly maintained in culture for weeks. Subsequent testing of various putative neuroprotectants in different models of in vitro ischemia produced results largely consistent with in vivo experimental or clinical trial experience, including lack of benefit for NXY-059, and a 4-6 hour window for benefit of hypothermic neuroprotection (Antonic et al., 2014).

Damian McLeod (Callaghan, Australia and Leipzig, Germany) presented in vivo data demonstrating a previously unknown and edema-independent mechanism of intracranial pressure (ICP) elevation 24 hours following stroke. Significant ICP elevation was found even after minor stroke with minimal subsequent edema. Interestingly, this increase was prevented by mild hypothermia in adult male Wistar and Sprague-Dawley rats (Murtha et al., 2014; Murtha et al., 2015). His data demonstrate that ICP elevation after stroke is a potential cause of the so called collateral failure in stroke-in-progression (Fig. 1). Neil Spratt explored potential mechanisms of this intracranial pressure rise based on data obtained from adult rats. Presence of ischemic penumbra in the early phases post stroke was associated with 24 hour ICP elevation, and there appears to be a triggering substance in the cerebrospinal fluid (Beard et al., 2016a, 2016b).

Renée Turner (Adelaide, Australia) presented data exploring the role of the neuropeptide substance $\mathrm{P}$ in development of cerebral edema and elevated ICP following large middle cerebral artery (MCA) stroke
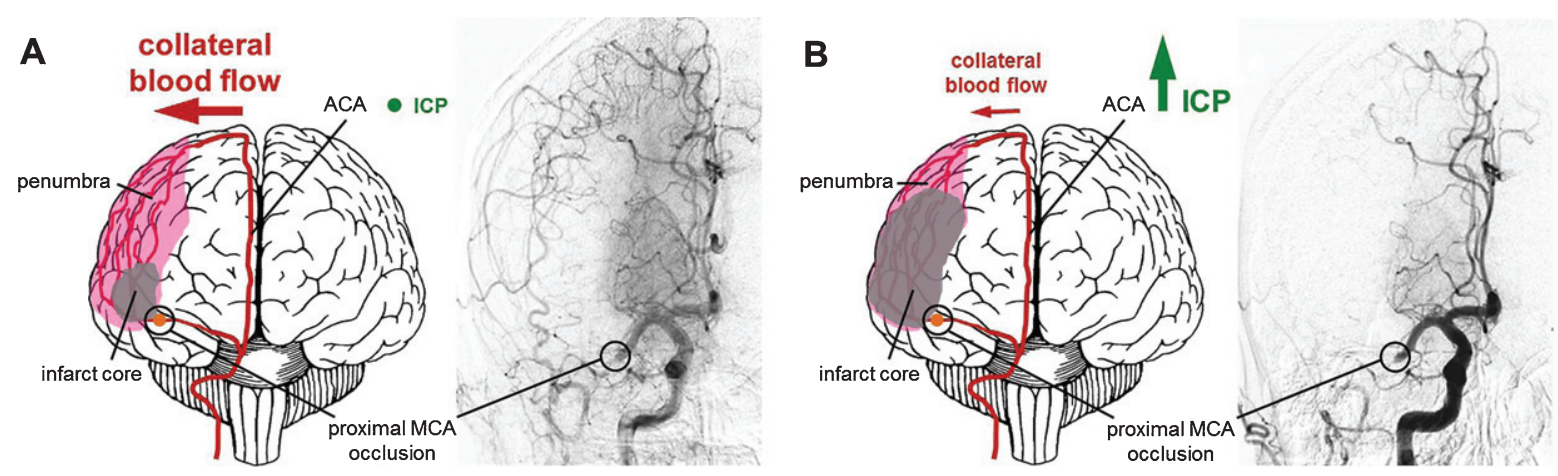

Fig. 1. Increase of infarct core volume due to ICP-caused collateral supply decline. (A) Collateral perfusion helps to limit the extent of the ischemic core after stroke if ICP remains low to moderate. (B) Steeply increasing ICP can dramatically reduce collateral blood flow after ischemic stroke, since the cerebral perfusion pressure equals to the mean arterial pressure minus ICP as suggested by the Monro-Kellie doctrine. Challenging conventional knowledge suggesting that edema is the major cause of ICP increase, Murtha and colleagues could show that even minor ischemic lesions causing mild edema might lead to significant ICP rises. This may represent an important pathophysiological mechanism contributing to significant cerebral damage even after initial minor strokes with larger penumbras with good collateralization. A potential therapeutic strategy might be the application of mild hypothermia, which has been demonstrated to prevent the ICP rise after even minor strokes. Angiograms were taken from Shuaib et al., 2011. 
in adult sheep. A neurokinin 1 antagonist prevented ICP elevation in this model, without the marked midline shift seen in untreated animals or some of those treated with decompressive craniectomy (Gabrielian et al., 2013). This may represent an alternative, less invasive approach to treating the edema associated with large MCA stroke (Corrigan et al., 2016).

Mhairi Macrae (Glasgow, United Kingdom) presented data regarding a promising theranostic based on Glasgow-Oxygen-Level-Dependent (GOLD) technology, which provides MRI-based diagnostic techniques for detection of penumbral tissue alongside improved oxygen delivery to maintain penumbra viability until blood supply is restored. Initial studies using rodent stroke models indicated both diagnostic and treatment potential, and subsequent studies have included testing in healthy volunteers and stroke patients, suggesting potential of these agents to maintain metabolism and prevent lactate elevation in the penumbra as observed in rats (Murtha et al., 2015; Robertson et al., 2015).

\subsection{Pathophysiology of vascular cognitive impairment}

Chronic cerebrovascular pathology is a leading cause of dementia, and arguably represents the most important modifiable risk factor for Alzheimer's disease (AD) (Iadecola, 2013). Despite this importance, the mechanisms and pathways contributing to vascular cognitive impairment (VCI) have largely remained elusive.

Gabor Petzold (Bonn, Germany) discussed the role of pro-inflammatory signaling cascades of the neurovascular unit in VCI. He provided evidence that an astrocyte-specific transgenic reduction of white matter inflammation in a mouse model of VCI can ameliorate axonal degeneration, demyelination and gliosis as well as cognitive decline. These data suggest that, similar to AD (Delekate et al., 2014), astrocytes might be centrally involved in the pathophysiology of VCI, and that anti-inflammatory interventions may prove therapeutically beneficial. Data were obtained in adult mice (10-14 weeks of age).

Linked to this work, Karen Horsburgh (Edinburgh, United Kingdom) discussed the contribution of microglial proliferation to axon-glial disruption and impairment of white matter function in a model of VCI. The VCI model is induced in male C57B1/6J wild-type mice (approx. 4 months old) by permanent bilateral carotid artery stenosis resulting in chronic cerebral hypoperfusion, axon-glial damage and progressive impairment of white matter function over three months. She demonstrated that targeting neuroinflammation dampens microglial proliferation and improves white matter function in 4 month old wild-type mice. In TgAPP (J9) mice (4 months old before the onset of amyloid deposition) after one-month reduced cerebral perfusion, the levels of pro-inflammatory proteins are markedly elevated. Further in another TgAPP model (TgSWDI mice aged 4 months) reduced perfusion over three months culminates in accumulation of vascular amyloid and degenerative changes. This work provides evidence that reduced cerebral hypoperfusion is a common mechanism underlying the pathophysiology of VCI and $\mathrm{AD}$ and that neuroinflammation may be a key target for intervention.

Costantino Iadecola (New York, USA) discussed the role of vascular factors in conditions associated with cognitive impairment and dementia. Hypertension, a major cause of VCI, blocks neurovascular coupling and impairs endothelial and blood-brain barrier function through reactive oxygen species (ROS) generated by NADPH oxidase 2 (Nox2). In models of $\mathrm{AD}$, there are major cerebrovascular alterations that precede amyloid deposition in the brain parenchyma (plaques) and blood vessels (amyloid angiopathy). The mechanisms involve binding of $A \beta$ to the scavenger receptor CD36, activation of Nox 2 and vascular oxidative stress as shown in a study using 3- to 4-mo-old male C57BL6/J or CD36 $6^{0 / 0}$, and Tg2576 mice (Park et al., 2011). Thus, deletion of CD36 rescues the cerebrovascular dysfunction in $\operatorname{Tg} 2576$ mice (aged 3, 18, and 22 months) and, remarkably, alleviates cerebral amyloid angiopathy without affecting amyloid plaques in the parenchyma (Park et al., 2013). Next, the lab investigated the mechanisms by which the ROS alter cerebrovascular function. It was found that $A \beta$ induces DNA damage and activation of the DNA repair enzyme polyADP ribose polymerase (PARP) in cerebral endothelial cells, leading to formation of polyADP ribose, activation of the ion channel TRPM2 by ADP ribose, massive increases in endothelial $\mathrm{Ca}^{2+}$, and endothelial dysfunction (Park et al., 2014). The latter study was performed in male 3- to 4-monthold C57BL/6J mice, and mice lacking PARP-1 or Nox2, as well as in Tg2576 and TRPM2-null mice. Collectively, these observations indicate that vascular alterations are important both in vascular and neurodegenerative dementias and suggest that targeting vascular risk factors and improving 
cerebrovascular function offers the opportunity to mitigate their devastating impact on human health.

Tim Murphy (Vancouver, Canada) described an adult (2-4 months old) mouse model of smallvessel disease that is characterized by occlusions resulting from endovascular injection of fluorescent microspheres that target $\sim 12 \mu \mathrm{m}$ diameter penetrating arterioles, which can be localized by histology (Silasi et al., 2015) or in vivo imaging. Advantages of the model are its simplicity with respect to surgery and ability to recover animals for long-term studies. Using Thy1-green fluorescent protein (GFP) transgenic mice, the impact of micro-occlusions on neuronal structure was determined. Micro-occlusions in the hippocampus led to microinfarcts in $\sim 7 \%$ of lodged microspheres cases, while axons within white matter tracts as well as the striatum and thalamus became bleb-like or disrupted. Neocortical layer 5 neurons were relatively resistant to structural damage, with $<2 \%$ of the lodged microspheres producing obvious neuronal damage by assessment of GFP-labeled dendrites. This small vessel disease model will be used for assessment of regional functional connectivity to understand how small sporadic lesions affect network dynamics. The model can be combined with new mouse home-cage imaging systems where image capture can be automated.

Tracy Farr (Nottingham, United Kingdom) has been using diffusion tensor imaging to explore structural changes in connectivity in the adult hypoperfused C57BL/6J mouse brain. Graph theory is a mathematical modeling technique that can advance our understanding of how the diseased brain changes by quantifying diffusion trajectories and converting them into a series of numbers. Hypoperfusion reduced the number of distinct groups of highly interconnected brain structures, though connectivity increased within these sub-groups. Some network parameters were excellent neuroimaging biomarkers, as they were accurate predictors of cognitive outcome.

\subsection{The role of blood in brain injury}

While the majority of strokes are of ischemic nature, mortality is comparably higher following hemorrhagic stroke, i.e. up to $50 \%$ within the first 30 days after the insult (van Asch et al., 2010). Bleeding can be caused by traumatic brain injury (TBI) or occur spontaneously in hemorrhagic strokes, while intracerebral (ICH) and subarachnoid hemorrhage (SAH) account for $15 \%$ and $5 \%$ of all strokes, respectively.
The hematoma increases intracranial pressure and is associated with oxidative stress, inflammation, and cell death (Mracsko \& Veltkamp, 2014; Pluta et al., 2009). However, the direct contribution of the vasculature, blood or its components to disease pathophysiology remains to be elucidated.

Recent studies suggest that early brain injury following SAH is caused by constriction of pial arterioles (Friedrich et al., 2012). Nikolaus Plesnila (Munich, Germany) demonstrated that nitric oxide inhalation improved vasospasm in both microvasculature and large cerebral vessels following SAH in mice (6-8 weeks old). In addition, it also reduced cerebral edema and neuronal cell death, increased survival and improved neurological function in the animals (Terpolilli et al., 2015).

Oliver Kempski (Mainz, Germany) showed that infusion of autologous blood in a rat model of acute subdural hematoma increased lesion growth, microglia and astrocyte activation and worsened behavioral deficits. Intracranial pressure and cerebral blood flow were comparable between both groups (Jussen et al., 2016).

Marietta Zille (New York, USA) systematically investigated cell death mechanisms in an in vitro model of hemorrhagic stroke in primary E15 CD1 mouse cortical neurons. Similar to ischemic stroke, hemorrhagic stroke appears to induce death via regulated necrosis, although preliminary data indicate that cell death is not via parthanatos but rather via necroptosis or ferroptosis, an iron-dependent form of cell death.

Breakdown of hemoglobin further leads to iron overload thought to mediate part of the observed neuronal toxicity following hemorrhage. Preclinical evidence suggests that the iron chelator deferoxamine mesylate (DFO) protects against hemorrhagic stroke in aged (18 months old) rats (Okauchi et al., 2009). Magdy Selim (Boston, USA) discussed the ongoing efforts to develop DFO as a treatment for ICH patients. A phase I clinical trial established that daily infusions of DFO after ICH are feasible and well tolerated without causing serious adverse events (Selim et al., 2011). However, a subsequent phase II clinical trial using high doses of DFO was stopped due to an increased incidence of acute respiratory distress syndrome (ClinicalTrials.gov NCT01662895), and a modified protocol (iDEF) is currently underway (ClinicalTrials.gov NCT02175225). Magdy Selim stressed that transitional research is difficult and imperfect. While initial supporting proof-of-concept animal data is important, ongoing bi-directional 
communications between basic researchers and clinicians are required at all stages. He also questioned the cost-effectiveness and reliability of phase-I, small, dose-finding, studies and spoke about the need for future evaluation of alternative approaches for drug delivery to minimize systemic toxicity.

The presented studies highlight that blood is a major contributor to cell death and outcome following hemorrhagic stroke. Future studies will further elucidate the underlying mechanisms and allow for development of novel therapeutic options for hemorrhagic stroke patients beyond the currently existing, more mechanistically driven approaches of hematoma evacuation, substitution of coagulation factors and blood pressure regulation.

\section{Getting closer with clinical translation}

\subsection{The role of large animal models of CNS injury}

Animal models are essential in understanding the complex pathophysiology of neurological diseases, with the selection of appropriate animal models being fundamental to clinical success. In recent years, there has been resurgence in the use of large animal models of CNS injury, for example stroke, traumatic brain injury and spinal cord injury. Such models provide an intermediate to validate interventions of outstanding promise identified in rodent models prior to clinical assessment, because such a rigorous step-wise validation is more likely to yield greater clinical success. Recent developments in animal models of CNS injury were presented in the symposium. Whilst the clinical translation of novel therapeutic agents for stroke has been extremely poor to date, Matthew Gounis highlighted that in contrast there has been great success in the translation of medical devices for mechanical thrombectomy. Indeed, combining in vitro (van der Marel et al., 2016; Chueh et al., 2012, 2013) with in vivo models (Gounis et al., 2013; Nogueira et al., 2012; van der Bom et al., 2011) was described as a way to provide evidence to direct device development and implementation.

Renée Turner (Adelaide, Australia) described a number of ovine CNS injury models including transient/permanent stroke (Wells et al., 2015), traumatic brain injury and concussion. The advantages of the sheep as a model for CNS injury were detailed. For

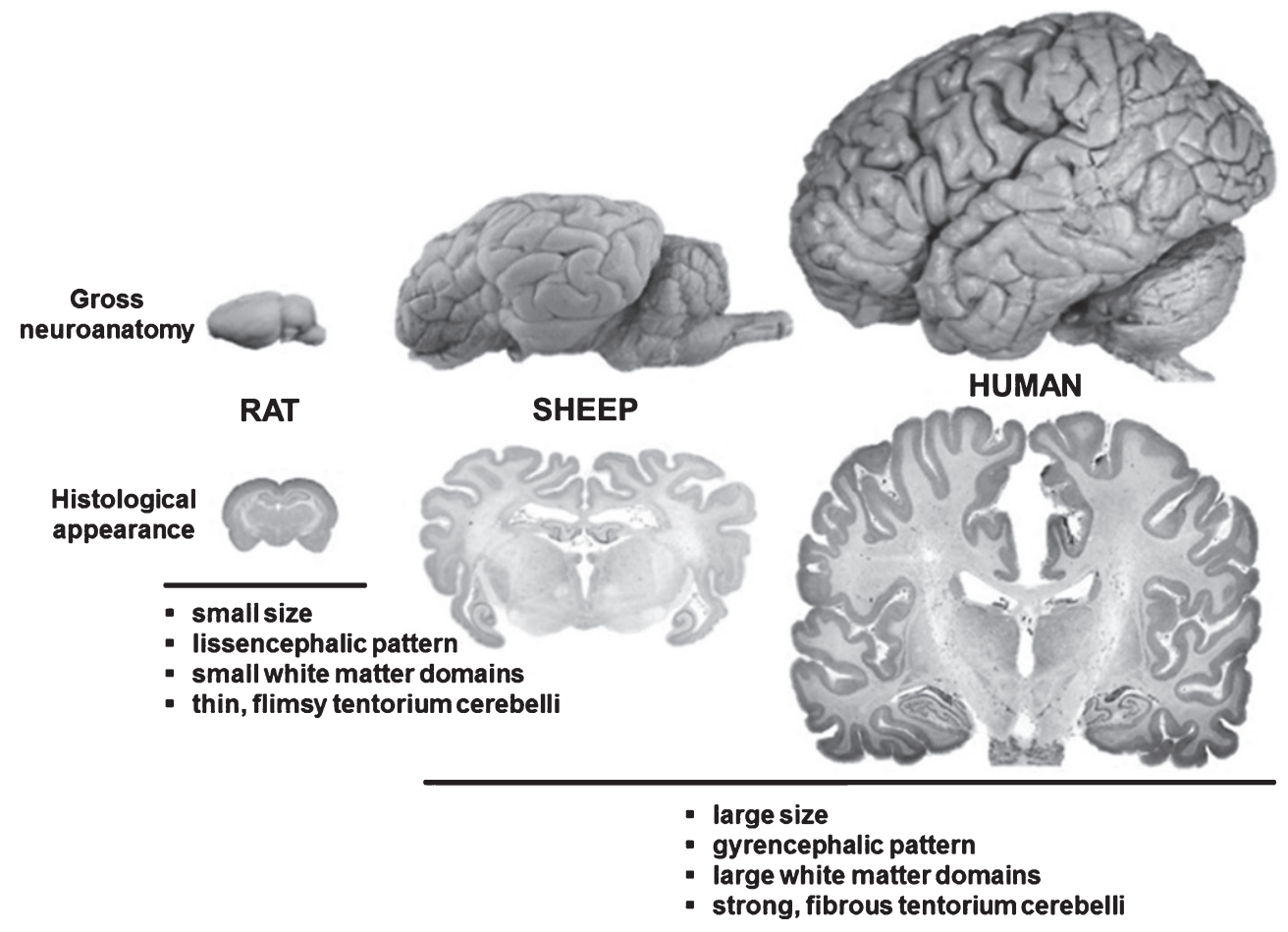

Fig. 2. Comparison between rodent, ovine and human brain. Although significantly smaller than the human brain, the ovine brain is also gyrencephalic and exhibits a grey-to-white-matter ration more similar to humans as compared to the rodent brains. Sheep are therefore considered an interesting model species for translational neuroscience. 
example, sheep have a more human-like brain structure (Fig. 2) that includes a gyrencephalic pattern, clear anatomical discrimination between grey and white matter (including dense white matter tracts), strong fibrous dura mater and tentorium cerebelli, and large size compared with the rodent brain, in addition to a remarkably similar cerebrovascular anatomy (with the exception of the rete mirabile).

Anna Leonard (Adelaide, Australia) outlined a porcine model of spinal cord injury and demonstrated the advantages of this model over smaller models. Particularly, the anatomical size of the spinal cord and intrathecal space, in addition to the ability to perform clinically relevant procedures, including imaging and intrathecal pressure monitoring, improve the potential translation to the clinic (Lee et al., 2013; Jones et al., 2012).

In summary, the number and quality of large animal models of CNS injury has increased tremendously over the past few years and may represent one approach to overcome the translational roadblock and improve outcome for patients with CNS injury.

\subsection{Current challenges and next steps for endovascular treatments}

In 2015, mechanical thrombectomy has robustly shown beneficial effects in large randomized clinical trials, mainly by demonstrating an improved functional outcome but also reduced lesion size and decreased mortality (Campbell et al., 2015). Clinicians are recently challenged by the optimum kind of sedation, since general anesthesia was found to be associated with a worsened outcome (Dhakal et al., 2015), the fastest track to recanalization while considering intra-hospital proceedings (e.g. characterized by the 'door-to-recanalization' time), and the increasing need of capacities for postinterventional intensive care. However, on the fringes of the 9th ISN\&N, neuroscientists and clinicians discussed about the potential impact of neuroprotective approaches that could be applied simultaneously with mechanical thrombectomy. Considering the lack of positive translations from hopeful pre-clinical neuroprotective strategies, the newly established kind of acute vessel re-opening via the intra-arterial route offers a potent chance to place neuroprotective drugs in close regional association to the initial, ischemia-affected tissue. In this direction, hopeful data originated from Michael E. Maniskas et al. (2016), who noted a significant decrease in lesion volume after intra-arterial application of verapamil subsequent to the recanalization of the middle cerebral artery in mice. In a more general perspective, new concepts for interacting within the complex pathways of neurotoxicity were discussed in the setting of acute vessel recanalization. Interesting data on this topic emerged from José Castillo et al. (2016), who reported on the difficile glutamate ratio between the blood and the brain, which could be modified by a group of pharmacological active substances working as 'glutamate grabber', potentially impeding effects emerging from a glutamate-related excitotoxicity.

These approaches might represent tasks for upcoming, translational-oriented studies, which, however, will require the close collaboration of basic neuroscientists, neurologists and neuroradiologists. Pre-clinical studies that started in well-established small animal models, exhibiting excellent standardization of environmental factors as well as lesion location and size, with confirming investigations in large animal studies might represent a hopeful way before strategies will be tested in the clinical setting.

\section{Central and peripheral immune responses in translational neurosciences}

\subsection{Immunity in post-stroke neuronal damage and repair}

Infiltration of inflammatory leukocytes is an established feature of human stroke. Currently, the activation of the immune system is recognized as a key mechanism in all stages of stroke pathophysiology, including neuronal plasticity and regeneration (Iadecola \& Anrather, 2011).

Mathias Gelderblom (Hamburg, Germany) pointed out that innate-like lymphocytes contribute to the tissue damage via local production of IL-17, which leads to a subsequent detrimental infiltration of neutrophils (Gelderblom et al., 2012). All data were obtained in models using adult mice. Kate Lykke Lambertsen demonstrated neuroprotective effects of microglial-derived transmembrane-TNF. She reported that the selective blockade of soluble$\mathrm{TNF}$ is associated with beneficial effects in a mouse model of experimental stroke (Madsen et al., 2015). Arthur Liesz (Munich, Germany) reviewed the role of post-stroke immunomodulation. He emphasized that cerebral ischemia results in a multiphasic dysbalance of the peripheral immune homeostasis. A strong over-activation of peripheral immunity in the acute phase is followed by a low-grade chronic 
inflammatory state in the chronic phase. Employing multiphoton microscopy, Jens Neumann (Magdeburg, Germany) reported data from rodent studies indicating that microglia are recruited to injured neurons, where they exert neuroprotective effects (Neumann et al., 2008). Finally, Halina Offner (Portland, USA) demonstrated the protective role of a sub-population of B cells, called regulatory B cells (Bregs). Data from her lab showed that IL-10 ${ }^{+}$ B-cells elicited protective effects by decreasing the proinflammatory status of the microglia, and by inducing an anti-inflammatory M2 phenotype in microglia in eight-week old female C57BL/6 wild-type mice (Benedek et al., 2016).

Overall, the talks highlighted recent developments in post-stroke immunology. On one side, divergent roles of immune cell subpopulations in inflammatory collateral damage and neuroprotection after stroke were addressed. On the other side, the differing roles of brain-invading leukocytes in the chronic stages after brain injury for neuronal regeneration and repair mechanisms were emphasized.

\subsection{The spleen as a novel target for stroke therapies}

The spleen session focused on the last 10 years of basic and clinical research supporting a role for the spleen in the pathophysiology of ischemic stroke. Halina Offner initially discussed her seminal discoveries that the spleen contracts after stroke and releases inflammatory cells into the circulation (Pennypacker \& Offner, 2015; Offner et al., 2006). These studies along with others in the field have stimulated research on the spleen, an important component of the immune response to stroke.

Dr. Offner (Portland, USA) discussed sex differences in spleen responses that have clear implications for the development of immunological based treatments in stroke patients (Banerjee et al., 2013). Consequently, the spleen became a potential target for new therapies. For example, Robert Mays (Cleveland, USA) discussed how a specific bone marrow-derived adherent stem cell line (MultiStem) may reduce brain injury and promote recovery through mechanisms involving the spleen. Dr. Mays presented the results of a double-blind, placebo-controlled clinical trial in which acute stroke patients were randomized to receive intravenous infusion of MultiStem or placebo within 24 to 48 hours after symptom onset (Hess et al., 2014). Sean Savitz (Houston, USA) then completed the session on clinical studies confirming that the spleen likely reduces in size in patients with acute stroke and that spleen contraction is associated with higher age, prior stroke, and African-American ethnicity. Data were also shown that serum inflammatory cytokines are significantly increased in patients with contracted spleens.

\section{System neuroscience: New concepts for functional regeneration}

\subsection{Roots and routes for stroke recovery}

Stroke leads to large-scale dysfunction of neural networks beyond the local site of ischemic brain injury. Reorganization of affected networks can foster functional recovery, which may be furthered with neurostimulation techniques. Consequently, assessment of stroke-induced impairments of brain circuits, post-stroke remodeling of functional and structural connections, and effects of neurorestorative treatments could lead to significant advancement in stroke diagnostics, prognostics and therapeutics (Dijkhuizen et al., 2014) (Fig. 3). Latest insights in the characteristics, impact and mutability of post-stroke neural network alterations were presented and discussed in the session 'Roots and routes for stroke recovery'.

Willem M. Otte (Utrecht, The Netherlands) explained how different network analysis methods inform on neural network topology from structural and functional magnetic resonance imaging (MRI) data. His studies in animal models and patients illustrated the difficulties of direct comparison between networks in control and pathological brains, which often differ in network density. Alternative strategies, such as minimum spanning tree and generative modeling (Sinke et al., 2016), can overcome these issues and allow more reliable characterization of topological network modifications after brain injury.

Adam Q. Bauer and Jin-Moo Lee (both St. Louis, USA) reported on changes in functional connectivity in the post-stroke mouse brain as measured with a relatively new functional imaging technique, based on optical intrinsic signals (White et al., 2011). Restoration of interhemispheric functional connectivity, which typically coincides with post-stroke sensorimotor recovery (Bauer et al., 2014), was impeded by optogenetic stimulation of the contralesional somatosensory cortex subacutely after photothrombotic stroke in the left somatosensory cortex. In a 


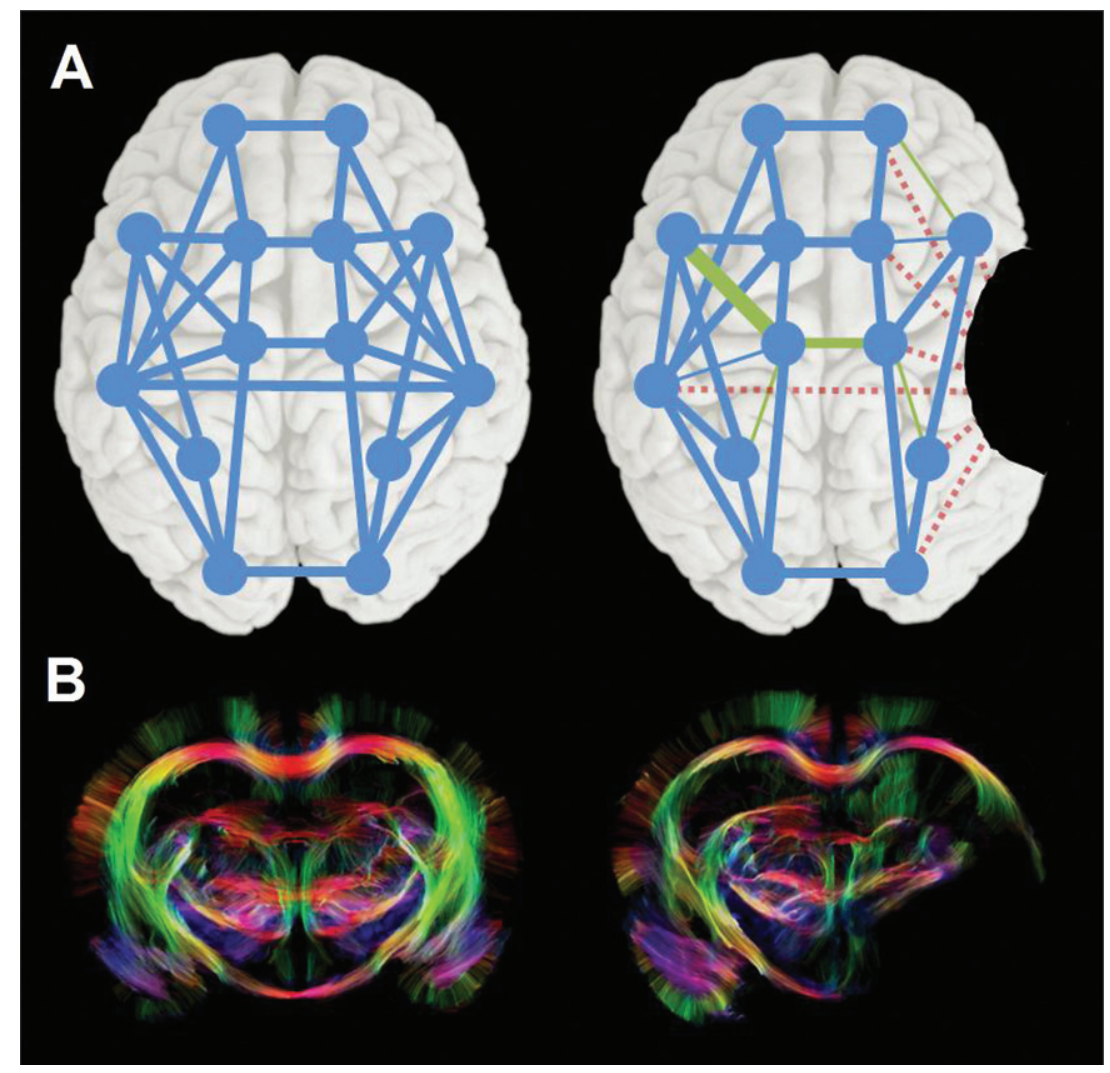

Fig. 3. Changes in neural network connectivity after stroke. (A) Schematic representation of a neural network in human brain before (left), with nodes and edges in blue, and after stroke (right), illustrating global disconnection (red dotted edges) and reorganization (green edges) as a result of a focal stroke lesion (black area). (B) Diffusion tensor imaging-based fiber tractography maps of control (left) and 10-weeks post-stroke rat brain (right), showing altered fiber pathway patterns in perilesional white matter chronically after stroke. Stroke was induced by 90 -min intraluminal occlusion of the right middle cerebral artery in adult male Sprague Dawley rats. High angular (120 directions) and spatial resolution $(0.2 \mathrm{~mm}$ isotropic voxels) diffusion-weighted MRI data were acquired post mortem on a $9.4 \mathrm{~T}$ animal MRI scanner (total scan time: $26 \mathrm{~h}$ ). MrTrix $3^{\circledR}$ software (http://www.mrtrix.org/) was used for diffusion-based tractography. Courtesy of Michel Sinke and Willem Otte.

parallel study, whisker deprivation enhanced functional remapping of the forelimb representation into the whisker barrel cortex, which was accompanied by improved behavioral recovery. Their studies clearly demonstrated how post-stroke cortical remapping and functional recovery may be influenced - negatively or positively - by specific modulation of brain activity in peri- or contralesional areas.

Randolph J. Nudo (Kansas City, USA) showed the potential of the promising concept of closed-loop neuromodulation in a rat model. Microelectrodes were implanted in the premotor cortex, and microdevices that discriminate individual action potentials, were used to process discriminated spikes from multiple input channels, in order to trigger electrical stimulation of the somatosensory cortex (Guggenmos et al., 2013). Continuing spike-triggered cortical stimulation through this closed-loop system effectively improved sensorimotor function after focal injury to the primary motor cortex, emphasizing the ability of neural interface systems to restore functional connectivity and promote recovery after brain damage.

\subsection{Neurorehabilitation, human brain plasticity and non-invasive neuromodulation}

Yun-Hee Kim (Seoul, Republic of Korea) provided an expert overview on brain stimulation for neural network plasticity after stroke. Based on recent findings that motor training can increase functional recovery by enhancing neuroplasticity in the cortico-spinal tract (Lazaridou et al., 2013), she critically reviewed the clinical impact on invasive and non-invasive stimulation paradigms. For example, high frequency repetitive transcranial magnetic 
stimulation (Chang et al., 2010) and bilateral transcranial direct current stimulation (tDCS, Sunwoo et al., 2013) can induce functional improvements in human stroke survivors in the subacute and chronic phase of stroke. A possible explanation was given by Maria Rüger (Cologne, Germany), who showed that tDCS can enhance recruitment of endogenous neuroprogenitor cells in the adult male Wistar rat (Rueger et al., 2012), being accompanied by improved functional outcome (Fig. 4).

Complex information processing and sensory functions may also benefit from non-invasive stimulation. Dorothee Saur (Leipzig, Germany) presented recent data on language network reorganization, including underlying dynamics and region-specific roles for recovery. She also introduced a potential rational for increasing language network reorganization using non-invasive brain stimulation based on the results of functional MRI in the sense of aneuroimaging-guided network stimulation. In addition, she presented the results of the study by Meinzer et al. (2016), which demonstrated increasing reorganization in the language network even when stimulation was applied to an ancillary non-damaged network, e.g. the motor network. Bernhard Sabel (Magdeburg, Germany) is an expert in partial blindness and vision restauration (Bola et al., 2014). He presented promising data on noninvasive repetitive transorbital alternating current stimulation, which induced long lasting (6 months and longer) vision improvements in patients suffering from optic neuropathy in clinical trials (Gall et al., 2011, 2016). The trial revealed a more than $20 \%$ larger visual field size and $60 \%$ better vision in impaired visual field sector.

Ulf Ziemann (Tübingen, Germany) reviewed current concepts for individualized non-invasive brain stimulation for neurorehabilitation. He showed evidence that non-invasive brain stimulation might change activity and excitability of brain networks and highlighted potential supporting effects in stroke rehabilitation. On the other hand, effect sizes using current stimulation paradigms seem limited. Combining stimulation with supportive therapies such as pharmacotherapies might help to further increase effect sizes (Ziemann et al., 2015), but large scale clinical trials still need to be conducted.
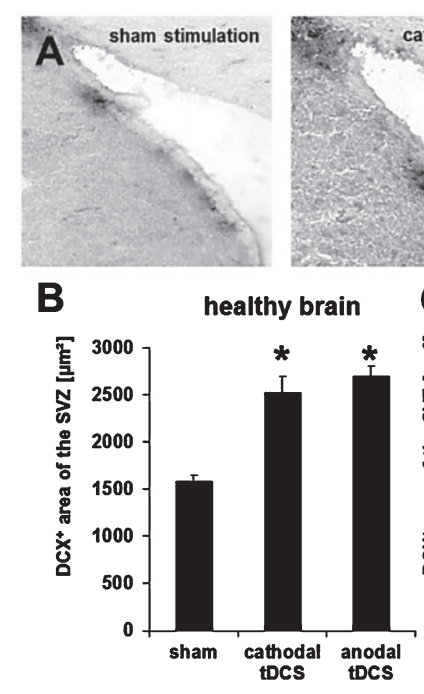
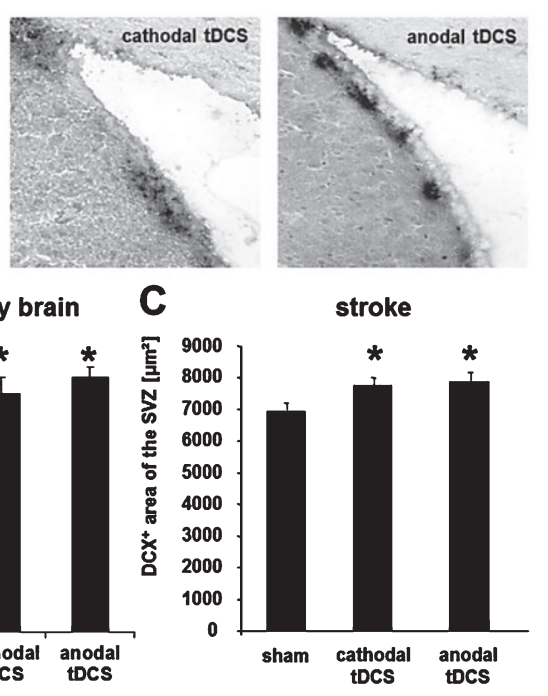

D
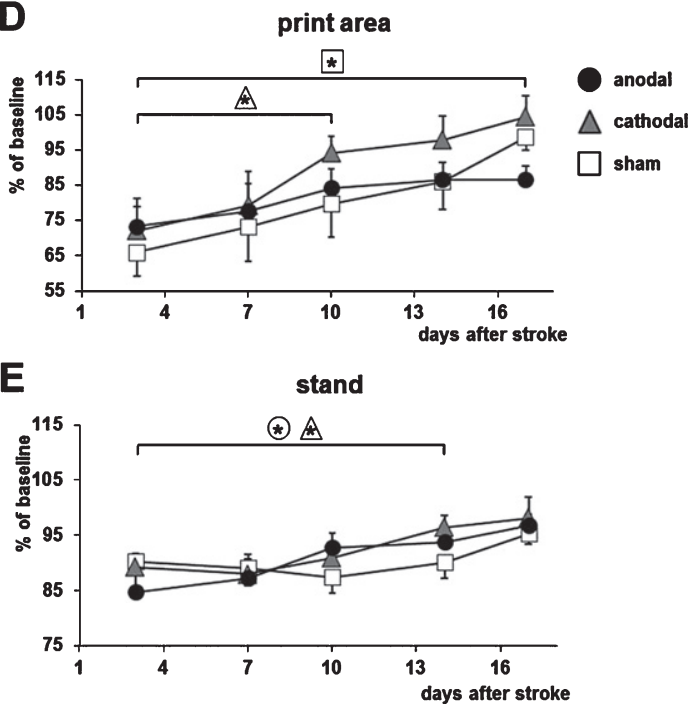

Fig. 4. Transcranial direct current stimulation (tDCS) induces neurogenesis and accelerates functional recovery after stroke in the rodent brain. (A) Neuroblasts in the subventricular zone (SVZ) were identified by their expression of doublecortin (DCX) under control conditions (sham, left) and after multi-session tDCS of cathodal (middle) or anodal (right) polarity. (B) Following multi-session tDCS of cathodal or anodal polarity, the area of DCX-positive neuroblasts in the SVZ ipsilateral to tDCS was wider than under control conditions in the healthy mouse brain (sham). (C) Rats subjected to focal cerebral ischemia by middle cerebral artery occlusion displayed a wider DCX+area of the SVZ when treated with tDCS of cathodal or anodal polarity for 10 consecutive days after stroke. (D) Motor recovery assessed by the Catwalk test revealed that multi-session cathodal tDCS led to a faster recovery of limb strength ('print area') in stroke rats compared to sham treatment. (E) Both cathodal and anodal tDCS facilitated recovery of gait, i.e., led to less limping ('stand'), compared to control $\left({ }^{*} p<0.05\right)$. Figure elements were modified from Pikhovych et al., 2016 and Braun et al., 2016 with permissions. 


\section{Conclusions and outlook}

The deepened understanding of pathophysiological mechanisms behind neurovascular disorders and a multitude of novel and well validated findings sustain the hope that our therapeutic options arsenal may be both augmented and improved in the mid-term future. On the other hand, the previous decades of unsuccessful therapeutic research in the field has yielded caution and exemplified the need for interdisciplinary collaboration to reflect complex clinical situations. This includes the detrimental interaction of common comorbidities with acute and chronic neurodegenerative disorders (Lucke-Wold et al., 2012). Consequently, novel ideas and collaborative concepts to overcome or at least bypass the still existing translational roadblock are intensively discussed throughout the neuroscience community (Boltze et al., 2016; Dirnagl et al., 2013) and the first multicenter preclinical trial was already concluded (Llovera et al., 2015). Next to its traditional topics, the 10 th ISN\&N will consequently also put the spotlight on these novel formats, systemic neuroscience and clinical translation. It will also feature a higher proportion of dementia-related research. The ISN\&N anniversary meeting will take place in April 2018 in Dresden, Germany (www.neurorepair-2018.de).

\section{Acknowledgments}

The authors want to thank all institutions and people who supported the 9th ISN\&N. Particularly, we express our gratitude for generous grants provided by the Deutsche Forschungsgemeinschaft (grant number: BO3518/1-1) and the International Society of Cerebral Blood Flow and Metabolism. We also thank all industrial sponsors and exhibitors for academic and financial support. We further want to acknowledge all co-workers who helped to organize the meeting and made it running smoothly. Special thanks go to the Eventlab congress organizing team for their invaluable and indefatigable support as well as for always favoring academic demands over accommodating budgetary constraints.

\section{ISN\&N meeting contributors}

This review paper highlights scientific work from the following colleagues who actively participated in the 9th ISN\&N meeting (in alphabetic order):
Adam Q. BAUER, Rona G. GIFFARD, Matthew J. GOUNIS, Victoria GRÖGER, Petra HENRICHNOACK, Stephan VON HÖRSTEN, David D. HOWELLS, Oliver KEMPSKI, Yun-Hee KIM, Kate L. LAMBERTSEN, Jin-Moo LEE, Anna LEONARD, Arthur LIESZ, I Mhairi MACRAE, Robert W. MAYS, Damian D. MCLEOD, Jens NEUMANN, Randolph J. NUDO, Halina OFFNER, Steffen ROSSNER, Magdy SELIM, Farida SOHRABJI, Kejie YIN, Jochen WALTER, Ulf ZIEMANN.

\section{References}

Antonic, A., Dottori, M., Leung, J., Sidon, K., Batchelor, P.E., Wilson, W., Macleod, M.R., \& Howells, D.W. (2014). Hypothermia protects human neurons. International Journal of Stroke, 9(5), 544-552.

Banerjee, A., Wang, J., Bodhankar, S., Vandenbark, A.A., Murphy, S.J., \& Offner, H. (2013). Phenotypic changes in immune cell subsets reflect increased infarct volume in male vs. female mice. Translational Stroke Research, 4(5), 554-563.

Bauer, A.Q., Kraft, A.W., Wright, P.W., Snyder, A.Z., Lee, J.M., \& Culver, J.P. (2014). Optical imaging of disrupted functional connectivity following ischemic stroke in mice. Neuroimage, 99, 388-401.

Beard, D.J., Murtha, L.A., McLeod, D.D., \& Spratt, N.J. (2016b). Intracranial pressure and collateral blood flow. Stroke, 47(6), $1695-1700$

Beard, D.J., Logan, C.L., McLeod, D.D., Hood, R.J., Pepperall, D., Murtha, L.A., \& Spratt, N.J. (2016a). Ischemic penumbra as a trigger for intracranial pressure rise - A potential cause for collateral failure and infarct progression? Journal of Cerebral Blood Flow and Metabolism, 36(5), 917-927.

Benedek, G., Zhang, J., Bodhankar, S., Nguyen, H., Kent, G., Jordan, K., Manning, D., Vandenbark, A.A., \& Offner, H. (2016). Estrogen induces multiple regulatory B cell subtypes and promotes M2 microglia and neuroprotection during experimental autoimmune encephalomyelitis. Journal of Neuroimmunology, 293, 45-53.

Bola, M., Gall, C., Moewes, C., Fedorov, A., Hinrichs, H., \& Sabel B.A. (2014). Brain functional connectivity network breakdown and restoration in blindness. Neurology, 83(6), 542-551.

Boltze, J., Kleinschnitz, C., Reymann, K.G., Reiser, G., Wagner, D.C., Kranz, A., Michalski, D., \& the meeting contributors (2012). Neurovascular pathophysiology in cerebral ischemia, dementia and the ageing brain - current trends in basic, translational and clinical research. Experimental and Translational Stroke Medicine, 10(4), 14.

Boltze, J., Kranz, A., Wagner, D.C., Reymann, K.G., Reiser, G., \& Hess, D.C. (2011). Recent advances in basic and translational stroke research. Expert Review of Neurotherapeutics, 11(2), 199-202.

Boltze, J., Wagner, D.C., Henninger, N., Plesnila, N., \& Ayata, C. (2016). Preclinical phase III trials in translational stroke research: Community response on framework and guidelines. Translational Stroke Research, 7(4), 241-247. 
Braun, R., Klein, R., Walter, H.L., Ohren, M., Freudenmacher, L., Getachew, K., Ladwig, A., Luelling, J., Neumaier, B., Endepols, H., Graf, R., Hoehn, M., Fink, G.R., Schroeter, M., \& Rueger, M.A. (2016). Transcranial direct current stimulation accelerates recovery of function, induces neurogenesis and recruits oligodendrocyte precursors in a rat model of stroke. Experimental Neurology, 279, 127-136.

Castillo, J., Loza, M.I., Mirelman, D., Brea, J., Blanco, M., Sobrino, T., \& Campos, F. (2016). A novel mechanism of neuroprotection: Blood glutamate grabber. Journal of Cerebral Blood Flow and Metabolism, 36, 292-301.

Campbell, B.C., Donnan, G.A., Lees, K.R., Hacke, W., Khatri, P., Hill, M.D., Goyal, M., Mitchell, P.J., Saver, J.L., Diener, H.C., \& Davis, S.M. (2015). Endovascular stent thrombectomy: The new standard of care for large vessel ischaemic stroke. Lancet Neurology, 14(8), 846-854.

Chang, W.H., Kim, Y.H., Bang, O.Y., Kim, S.T., Park, Y.H., \& Lee, P.K. (2010). Long-term effects of rTMS on motor recovery in patients after subacute stroke. Journal of Rehabilitation Medicine, 42(8), 758-764.

Chevilley, A., Lesept, F., Lenoir, S., Ali, C., Parcq, J., \& Vivien, D. (2015). Impacts of tissue-type plasminogen activator (tPA) on neuronal survival. Frontiers in Cellular Neuroscience, 9, 415 .

Chueh, J.Y., Kühn, A.L., Puri, A.S., Wilson, S.D., Wakhloo, A.K., \& Gounis, M.J. (2013). Reduction in distal emboli with proximal flow control during mechanical thrombectomy: A quantitative in vitro study. Stroke, 44(5), 1396-1401.

Chueh, J.Y., Wakhloo, A.K., \& Gounis, M.J. (2012). Effectiveness of mechanical endovascular thrombectomy in a model system of cerebrovascular occlusion. American Journal of Neuroradiology, 33(10), 1998-2003.

Corrigan, F., Vink, R., \& Turner, R.J. (2016). Inflammation in acute CNS injury: A focus on the role of substance P. British Journal of Pharmacology, 173(4), 703-715.

Deak, F., Freeman, W.M., Ungvari, Z., Csiszar, A., \& Sonntag, W.E. (2016). Recent developments in understanding brain aging: Implications for Alzheimer's disease and vascular cognitive impairment. The Journals of Gerontology. Series A, Biological Sciences and Medical Sciences, 71(1), 13-20.

Delekate, A., Füchtemeier, M., Schumacher, T., Ulbrich, C., Foddis, M., \& Petzold, G.C. (2014). Metabotropic P2Y1 receptor signalling mediates astrocytic hyperactivity in vivo in an Alzheimer's disease mouse model. Nature Communications, 5,5422 .

Diener, H.C., Lees, K.R., Lyden, P., Grotta, J., Davalos, A., Davis, S.M., Shuaib, A., Ashwood, T., Wasiewsk, W., Alderfer, V., Hårdemark, H.G., Rodichok, L., \& SAINT I and II Investigators (2008). NXY-059 for the treatment of acute stroke: Pooled analysis of the SAINT I and II Trials. Stroke, 39, 1751-1758.

Dhakal, L.P., Diaz-Gomez, J.L., \& Freeman, W.D. (2015). Role of anesthesia for endovascular treatment of ischemic stroke: Do we need neurophysiological monitoring? Stroke, 46, 17481754.

Dijkhuizen, R.M., Zaharchuk, G., \& Otte, W.M. (2014). Assessment and modulation of resting-state neural networks after stroke. Current Opinion in Neurology, 27(6), 637-643.
Dirnagl, U., Hakim, A., Macleod, M., Fisher, M., Howells, D. Alan, S.M., Steinberg, G., Planas, A.M., Boltze, J., Savitz, S., Iadecola, C., \& Meairs, S. (2013). A concerted appeal for international cooperation in preclinical stroke research. Stroke, 44(6), 1754-1760.

Emmer, A., Staege, M.S., \& Kornhuber, M.E. (2014). The retrovirus/superantigen hypothesis of multiple sclerosis. Cellular and Molecular Neurobiology, 34(8), 1087-1096.

Friedrich, B., Muller, F., Feiler, S., Scholler, K., \& Plesnila, N. (2012). Experimental subarachnoid hemorrhage causes early and long-lasting microarterial constriction and microthrombosis: An in-vivo microscopy study. Journal of Cerebral Blood Flow and Metabolism, 32, 447-455.

Gabrielian, L., Helps, S.C., Thornton, E., Turner, R.J., Leonard, A.V., \& Vink, R. (2013). Substance P antagonists as a novel intervention for brain edema and raised intracranial pressure. Acta Neurochirurgica Supplement, 118, 201-204.

Gall, C., Schmidt, S., Schittkowski, M.P., Antal, A., Ambrus, G.G., Paulus, W., Dannhauer, M., Michalik, R., Mante, A., Bola, M., Lux, A., Kropf, S., Brandt, S.A., \& Sabel, B.A. (2016). Alternating current stimulation for vision restoration after optic nerve damage: A randomized clinical trial. Public Library of Science One, 11(6), e0156134.

Gall, C., Sgorzaly, S., Schmidt, S., Brandt, S., Fedorov, A., \& Sabel, B.A. (2011). Noninvasive transorbital alternating current stimulation improves subjective visual functioning and vision-related quality of life in optic neuropathy. Brain Stimulation, 4(4), 175-188.

Gelderblom, M., Weymar, A., Bernreuther, C., Velden, J., Arunachalam, P., Steinbach, K., Orthey, E., Arumugam, T.V., Leypoldt, F., Simova, O., Thom, V., Friese, M.A., Prinz, I., Hölscher, C., Glatzel, M., Korn, T., Gerloff, C., Tolosa, E., \& Magnus, T. (2012). Neutralization of the IL-17 axis diminishes neutrophil invasion and protects from ischemic stroke. Blood, 120(18), 3793-3802.

Gounis, M.J., Wakhloo, A.K., \& Chueh, J.Y. (2013). Preclinical investigations for thrombectomy devices-does it translate to humans? Stroke, 44(6 Suppl 1), S7-S10.

Guggenmos, D.J., Azin, M., Barbay, S., Mahnken, J.D., Dunham, C., Mohseni, P., Nudo, R.J., \& Restoration of function after brain damage using a neural prosthesis (2013). Proceedings of the National Academy of Sciences of the United States of America, 110(52), 21177-21182.

Hacke, W., Kaste, M., Bluhmki, E., Brozman, M., Dávalos, A., Guidetti, D., Larrue, V., Lees, K.R., Medeghri, Z., Machnig, T., Schneider, D., von Kummer, R., Wahlgren, N., Toni, D., \& ECASS Investigators (2008). Thrombolysis with alteplase 3 to 4.5 hours after acute ischemic stroke. New England Journal of Medicine, 359, 1317-1329.

Henninger, N., \& Fisher, M. (2016). Extending the Time Window for Endovascular and Pharmacological Reperfusion. Translational Stroke Research, 7(4), 284-293.

Hess, D.C., Sila, C.A., Furlan, A.J., Wechsler, L.R., Switzer, J.A., \& Mays, R.W. (2014). A double-blind placebo-controlled clinical evaluation of MultiStem for the treatment of ischemic stroke. International Journal of Stroke, 9(3), 381-386.

Howells, D.W., \& Macleod, M.R. (2013). Evidence-based translational medicine. Stroke, 44(5), 1466-1471. 
Iadecola, C. (2013). The pathobiology of vascular dementia. Neuron, $80,844-866$.

Iadecola, C., \& Anrather, J. (2011). The immunology of stroke: From mechanisms to translation. Nature Medicine, 17, 796808.

Jones, C.F., Newell, R.S., Lee, J.H., Cripton, P.A., \& Kwon, B.K. (2012). The pressure distribution of cerebrospinal fluid responds to residual compression and decompression in an animal model of acute spinal cord injury. Spine, 37(23), E1422-E1431.

Jussen, D., Krenzlin, H., Papaioannou, C., Ens, S., Kempski, O., \& Alessandri, B. (2016). Blood aggravates histological and functional damage after acute subdural hematoma in rats. Journal of Neurotrauma, in press, doi:10.1089/neu.2016.4464

Kaiser, D., Weise, G., Möller, K., Scheibe, J., Pösel, C., Baasch, S., Gawlitza, M., Lobsien, D., Diederich, K., Minnerup, J., Kranz, A., Boltze, J., Wagner, D.C. (2014). Spontaneous white matter damage, cognitive decline and neuroinflammation in middle-aged hypertensive rats: An animal model of early-stage cerebral small vessel disease. Acta Neuropathologica Communications, 2, 169.

Kim, T., Mehta, S.L., Kaimal, B., Lyons, K., Dempsey, R.J., \& Vemuganti, R. (2016). Post-stroke induction of $\alpha$-synuclein mediates ischemic brain damage. Journal of Neuroscience, 36(26), 7055-7065.

Kummer, M.P., \& Heneka, M.T. (2014). Truncated and modified amyloid-beta species. Alzheimer's Research \& Therapy, 6(3), 28.

Lazaridou, A., Astrakas, L., Mintzopoulos, D., Khanicheh, A., Singhal, A.B., Moskowitz, M.A., Rosen, B., \& Tzika, A.A. (2016). Diffusion tensor and volumetric magnetic resonance imaging using an MR-compatible hand-induced robotic device suggests training-induced neuroplasticity in patients with chronic stroke. International Journal of Molecular Medicine, 32(5), 995-1000.

Lee, J.H., Jones, C.F., Okon, E.B., Anderson, L., Tigchelaar, S., Kooner, P., Godbey, T., Chua, B., Gray, G., Hildebrandt, R., Cripton, P., Tetzlaff, W., \& Kwon, B.K. (2013). A novel porcine model of traumatic thoracic spinal cord injury. Journal of Neurotrauma, 30(3), 142-159.

Llovera, G., Hofmann, K., Roth, S., Salas-Pérdomo, A., FerrerFerrer, M., Perego, C., Zanier, E.R., Mamrak, U., Rex, A., Party, H., Agin, V., Fauchon, C., Orset, C., Haelewyn, B., De Simoni, M.G., Dirnagl, U., Grittner, U., Planas, A.M., Plesnila, N., Vivien, D., \& Liesz, A. (2015). Results of a preclinical randomized controlled multicenter trial (pRCT): Anti-CD49d treatment for acute brain ischemia. Science Translational Medicine, 7(299), 299ra121.

Lo, E.H., \& Ning, M. (2016). Mechanisms and challenges in translational stroke research. Journal of Investigative Medicine, 64(4), 827-829.

Lucke-Wold, B.P., Turner, R.C., Lucke-Wold, A.N., Rosen, C.L., \& Huber, J.D. (2012). Age and the metabolic syndrome as risk factors for ischemic stroke: Improving preclinical models of ischemic stroke. Yale Journal of Biology and Medicine, 85(4), 523-539.

Madsen, P.M., Clausen, B.H., Degn, M., Thyssen, S., Kristensen, L.K., Svensson, M., Ditzel, N., Finsen, B., Deierborg, T., Brambilla, R., \& Lambertsen, K.L. (2015). Genetic ablation of soluble tumor necrosis factor with preservation of membrane tumor necrosis factor is associated with neuroprotection after focal cerebral ischemia. Journal of Cerebral Blood Flow and Metabolism, 36(9), 1553-1569.

Mandler, M., Walker, L., Santic, R., Hanson, P., Upadhaya, A.R., Colloby, S.J., Morris, C.M., Thal, D.R., Thomas, A.J., Schneeberger, A., \& Attems, J. (2014). Pyroglutamylated amyloid- $\beta$ is associated with hyperphosphorylated tau and severity of Alzheimer's disease. Acta Neuropathologica, 128(1), 67-79.

Maniskas, M.E., Roberts, J.M., Aron, I., Fraser, J.F., \& Bix, G.J. (2016). Stroke neuroprotection revisited: Intra-arterial verapamil is profoundly neuroprotective in experimental acute ischemic stroke. Journal of Cerebral Blood Flow and Metabolism, 36, 721-730.

Mehta, S.L., Kim, T., \& Vemuganti, R. (2015). Long noncoding RNA FosDT promotes ischemic brain injury by interacting with REST-associated chromatin-modifying proteins. Journal of Neuroscience, 35(50), 16443-16449.

Meinzer, M., Darkow, R., Lindenberg, R., \& Flöel, A. (2016). Electrical stimulation of the motor cortex enhances treatment outcome in post-stroke aphasia. Brain, 139(Pt 4), 1152-1163.

Morawski, M., Schilling, S., Kreuzberger, M., Waniek, A., Jäger, C., Koch, B., Cynis, H., Kehlen, A., Arendt, T., Hartlage-Rübsamen, M., Demuth, H.U., \& Roßner, S. (2014). Glutaminyl cyclase in human cortex: Correlation with (pGlu)amyloid- $\beta$ load and cognitive decline in Alzheimer's disease. Journal of Alzheimer's Disease, 39(2), 385-400.

Mracsko, E., Veltkamp, R., \& Neuroinflammation after intracerebral hemorrhage. (2014). Frontiers in Cellular Neuroscience, $8,388$.

Murphy, T.H., Li, P., Betts, K., \& Liu, R. (2008). Two-photon imaging of stroke onset in vivo reveals that NMDA-receptor independent ischemic depolarization is the major cause of rapid reversible damage to dendrites and spines. Journal of Neuroscience, 28(7), 1756-1772.

Murtha, L.A., McLeod, D.D., McCann, S.K., Pepperall, D., Chung, S., Levi, C.R., Calford, M.B., \& Spratt, N.J. (2014). Shortduration hypothermia after ischemic stroke prevents delayed intracranial pressure rise. International Journal of Stroke (5), 553-559.

Murtha, L.A., McLeod, D.D., Pepperall, D., McCann, S.K., Beard, D.J., Tomkins, A.J., Holmes, W.M., McCabe, C., Macrae, I.M., \& Spratt, N.J. (2015). Intracranial pressure elevation after ischemic stroke in rats: Cerebral edema is not the only cause, and short-duration mild hypothermia is a highly effective preventive therapy. Journal of Cerebral Blood Flow and Metabolism, 35(4), 592-600.

Neumann, J., Sauerzweig, S., Rönicke, R., Gunzer, F., Dinkel, K., Ullrich, O., Gunzer, M., \& Reymann, K.G. (2008). Microglia cells protect neurons by direct engulfment of invading neutrophil granulocytes: A new mechanism of CNS immune privilege. Journal of Neuroscience, 28(23), 5965-5975.

Nogueira, R.G., Levy, E.I., Gounis, M., \& Siddiqui, A.H. (2011). The Trevo device: Preclinical data of a novel stroke thrombectomy device in two different animal models of arterial thrombo-occlusive disease. Journal of Neurointerventional Surgery, 4(4), 295-300. 
Offner, H., Subramanian, S., Parker, S.M., Wang, C., Afentoulis, M.E., Lewis, A., Vandenbark, A.A., \& Hurn, P.D. (2006). Splenic atrophy in experimental stroke is accompanied by increased regulatory $\mathrm{T}$ cells and circulating macrophages. Journal of Immunology, 176(11), 6523-6531.

Okauchi, M., Hua, Y., Keep, R.F., Morgenstern, L.B., Schallert, T., \& Xi, G. (2010). Deferoxamine treatment for intracerebral hemorrhage in aged rats: Therapeutic time window and optimal duration. Stroke, 41, 375-382.

Ouyang, Y.B., Stary, C.M., White, R.E., \& Giffard, R.G. (2015). The use of microRNAs to modulate redox and immune response to stroke. Antioxidants \& Redox Signaling, 22(2), 187-202.

Pandi, G., Nakka, V.P., Dharap, A., Roopra, A., \& Vemuganti, R. (2013). MicroRNA miR-29c down-regulation leading to derepression of its target DNA methyltransferase 3a promotes ischemic brain damage. Public Library of Science One, 8(3), e58039.

Park, L., Wang, G., Moore, J., Girouard, H., Zhou, P., Anrather, J., Iadecola, C. (2014). The key role of transient receptor potential melastatin- 2 channels in amyloid- $\beta$-induced neurovascular dysfunction. Nature Communications, 5, 5318.

Park, L., Wang, G., Zhou, P., Zhou, J., Pitstick, R., Previti, M.L., Younkin, L., Younkin, S.G., Van Nostrand, W.E., Cho, S., Anrather, J., Carlson, G.A., \& Iadecola, C. (2011). Scavenger receptor CD36 is essential for the cerebrovascular oxidative stress and neurovascular dysfunction induced by amyloidbeta. Proceedings of the National Academy of Sciences of the United States of America, 108, 5063-5068.

Park, L., Zhou, J., Zhou, P., Pistick, R., El Jamal, S., Younkin, L., Pierce, J., Arreguin, A., Anrather, J., Younkin, S.G., Carlson, G.A., McEwen, B.S., \& Iadecola, C. (2013). Innate immunity receptor CD36 promotes cerebral amyloid angiopathy. Proceedings of the National Academy of Sciences of the United States of America, 110, 3089-3094.

Pennypacker, K.R., \& Offner, H. (2015). The role of the spleen in ischemic stroke. Journal of Cerebral Blood Flow and Metabolism, 35, 186-187.

Pluta, R.M., Hansen-Schwartz, J., Dreier, J., Vajkoczy, P., Macdonald, R.L., Nishizawa, S., Kasuya, H., Wellman, G., Keller, E., Zauner, A., Dorsch, N., Clark, J., Ono, S., Kiris, T., Leroux, P., \& Zhang, J.H. (2009). Cerebral vasospasm following subarachnoid hemorrhage: Time for a new world of thought. Neurological Research, 31, 151-158.

Pikhovych, A., Walter, H.L., Mahabir, E., Fink, G.R., Graf, R., Schroeter, M., \& Rueger, M.A. (2016). Transcranial direct current stimulation in the male mouse to promote recovery after stroke. Laboratory Animals, 50(3), 212-216.

Robertson, C.A., McCabe, C., Lopez-Gonzalez, M.R., Deuchar, G.A., Dani, K., Holmes, W.M., Muir, K.W., Santosh, C., \& Macrae, I.M. (2015). Detection of ischemic penumbra using combined perfusion and $\mathrm{T} 2 *$ oxygen challenge imaging. International Journal of Stroke, 10(1), 42-50.

Rezaei-Ghaleh, N., Amininasab, M., Kumar, S., Walter, J., \& Zweckstetter, M. (2016). Phosphorylation modifies the molecular stability of $\beta$-amyloid deposits. Nature Coтmиnications, 7, 11359.

Rueger, M.A., Keuters, M.H., Walberer, M., Braun, R., Klein, R., Sparing, R., Fink, G.R., Graf, R., \& Schroeter, M. (2012).
Multi-session transcranial direct current stimulation (tDCS) elicits inflammatory and regenerative processes in the rat brain. PLoS One, 7(8), e43776.

Selim, M., Yeatts, S., Goldstein, J.N., Gomes, J., Greenberg, S., Morgenstern, L.B., Schlaug, G., Torbey, M., Waldman, B., Xi, G., Palesch, Y., \& Deferoxamine Mesylate in Intracerebral Hemorrhage Investigators. (2011). Safety and tolerability of deferoxamine mesylate in patients with acute intracerebral hemorrhage. Stroke, 42, 3067-3074.

Selvamani, A., Sathyan, P., Miranda, R.C., \& Sohrabji, F. (2012). An antagomir to microRNA Let7f promotes neuroprotection in an ischemic stroke model. Public Library of Science One, $7(2), \mathrm{e} 32662$

Shuaib, A., Butcher, K., Mohammad, A.A., Saqqur, M., \& Liebeskind, D.S. Collateral blood vessels in acute ischaemic stroke: A potential therapeutic target. Lancet Neurology, 10(10), 909921.

Silasi, G., She, J., Boyd, J.D., Xue, S., Murphy, T.H. (2015). A mouse model of small-vessel disease that produces brain-wide-identified microocclusions and regionally selective neuronal injury. Journal of Cerebral Blood Flow and Metabolism, 35, 734-738.

Sinke, M.R., Dijkhuizen, R.M., Caimo, A., Stam, C.J., \& Otte, W.M. (2016). Bayesian exponential random graph modeling of whole-brain structural networks across lifespan. Neuroimage, 135, 79-91.

Sunwoo, H., Kim, Y.H., Chang, W.H., Noh, S., Kim, E.J., \& Ko, M.H. (2013). Effects of dual transcranial direct current stimulation on post-stroke unilateral visuospatial neglect. Neuroscience Letters, 554, 94-98.

Terpolilli, N.A., Feiler, S., Dienel, A., Muller, F., Heumos, N., Friedrich, B., Stover, J., Thal, S., Schöller, K., \& Plesnila, N. (2015). Nitric oxide inhalation reduces brain damage, prevents mortality, and improves neurological outcome after subarachnoid hemorrhage by resolving early pial microvasospasms. Journal of Cerebral Blood Flow and Metabolism, in press, doi: 10.1177/0271678X15605848

Van Asch, C.J., Luitse, M.J., Rinkel, G.J., van der Tweel, I., Algra, A., \& Klijn, C.J. (2010). Incidence, case fatality, and functional outcome of intracerebral haemorrhage over time, according to age, sex, and ethnic origin: A systematic review and meta-analysis. The Lancet Neurology, 9, 167-176.

van der Bom, I.M., Mehra, M., Walvick, R.P., Chueh, J.Y., \& Gounis, M.J. (2012). Quantitative evaluation of C-arm CT cerebral blood volume in a canine model of ischemic stroke. American Journal of Neuroradiology, 33(2), 353-358.

van der Marel, K., Chueh, J.Y., Brooks, O.W., King, R.M., Marosfoi, M.G., Langan, E.T., Carniato, S.L., Gounis, M.J., Nogueira, R.G., \& Puri, A.S. (2016). Quantitative assessment of device-clot interaction for stent retriever thrombectomy. Journal of Neurointerventional Surgery. in press, doi: 10.1136/neurintsurg-2015-012209

Venigalla, M., Sonego, S., Gyengesi, E., Sharman, M.J., \& Münch, G. (2016). Novel promising therapeutics against chronic neuroinflammation and neurodegeneration in Alzheimer's disease. Neurochemistry International, 95, 63-74.

Wells, A.J., Vink, R., Helps, S.C., Knox, S.J., Blumbergs, P.C., \& Turner, R.J. (2015). Elevated intracranial pressure and cerebral edema following permanent MCA occlusion in an ovine model. PLoS One, 10(6), e0130512. 
White, B.R., Bauer, A.Q., Snyder, A.Z., Schlaggar, B.L., Lee, J.M., \& Culver, J.P. (2011). Imaging of functional connectivity in the mouse brain. Public Library of Science One, 6(1), e16322.

Wu, F., Catano, M., Echeverry, R., Torre, E., Haile, W.B., An, J., Chen, C., Cheng, L., Nicholson, A., Tong, F.C., Park, J., \& Yepes, M. (2014). Urokinase-type plasminogen activator promotes dendritic spine recovery and improves neurological outcome following ischemic stroke. Journal of Neuroscience, 34(43), 14219-14232.

Wu, F., Torre, E., Cuellar-Giraldo, D., Cheng, L., Yi, H., Bichler, E.K., García, P.S., \& Yepes, M. (2015). Tissue-type plasminogen activator triggers the synaptic vesicle cycle in cerebral cortical neurons. Journal of Cerebral Blood Flow and Metabolism, 35(12), 1966-1976.
Xu, L.J., Ouyang, Y.B., Xiong, X., Stary, C.M., \& Giffard, R.G. (2015). Post-stroke treatment with miR-181 antagomir reduces injury and improves long-term behavioral recovery in mice after focal cerebral ischemia. Experimental Neurology, $264,1-7$.

Yin, K.J., Olson, K., Hamblin, M., Zhang, J.F., Schwendeman, S.P., \& Chen, Y.E. (2012). Vascular endothelial cellspecific microRNA-15a inhibits angiogenesis in hindlimb ischemia. Journal of Biological Chemistry, 287(32), 27055-27064.

Ziemann, U., Reis, J., Schwenkreis, P., Rosanova, M., Strafella, A., Badawy, R., \& Müller-Dahlhaus, F. (2015). TMS and drugs revisited 2014. Clinical Neurophysiology, 126(10), 18471868. 